\title{
Pictures Matter: How Images of Projected Sea-Level Rise Shape Long-Term Sustainable Design Decisions for Infrastructure Systems
}

\author{
Julie Milovanovic ${ }^{1}$, Tripp Shealy ${ }^{1, *(\mathbb{D}}$, Leidy Klotz ${ }^{2}$, Eric J. Johnson ${ }^{3}$ and Elke U. Weber ${ }^{4}$ \\ 1 Department of Civil and Environmental Engineering, Virginia Tech, Blacksburg, VA 24061, USA; \\ jmilovanovic@vt.edu \\ 2 Department of Systems and Information Engineering, University of Virginia, Charlottesville, VA 22903, USA; \\ 1k6me@virginia.edu \\ 3 Columbia Business School, Columbia University, New York, NY 10027, USA; ejj3@columbia.edu \\ 4 Department of Psychology, Princeton University, Princeton, NJ 08544, USA; eweber@princeton.edu \\ * Correspondence: tshealy@vt.edu
}

\section{check for}

updates

Citation: Milovanovic, J.; Shealy, T.; Klotz, L.; Johnson, E.J.; Weber, E.U. Pictures Matter: How Images of Projected Sea-Level Rise Shape Long-Term Sustainable Design Decisions for Infrastructure Systems. Sustainability 2022, 14, 3007. https:// doi.org/10.3390/su14053007

Academic Editors: Wen-Bin Chiou, Paichi Pat Shein and Ali Bahadori-Jahromi

Received: 30 December 2021

Accepted: 2 March 2022

Published: 4 March 2022

Publisher's Note: MDPI stays neutral with regard to jurisdictional claims in published maps and institutional affiliations.

Copyright: () 2022 by the authors. Licensee MDPI, Basel, Switzerland. This article is an open access article distributed under the terms and conditions of the Creative Commons Attribution (CC BY) license (https:// creativecommons.org/licenses/by/ $4.0 /)$.

\begin{abstract}
Community input matters in long-term decisions related to climate change, including the development of public infrastructure. In order to assess the effect of different ways of informing the public about infrastructure projects, a sample of people in the United States $(n=630)$ was provided with a case study concerning the redevelopment of the San Diego Airport. Participants received the same written information about the projected future condition of the airport. In addition, participants received images either portraying current conditions or portraying conditions in 2100 based on NOAA (National Oceanic and Atmospheric Administration) sea-level rise data. Participants were asked to choose 7 out of 21 design options to implement in the redevelopment project. The framework used for the design options stemmed from the Envision rating system. We analyzed the participants' selection of the credits using generalized linear mixed models. Those that received the images portraying the future were significantly more likely to select design options that would reduce the risk of climate change and flooding. Images portraying sea-level rise had different effects depending on participant demographics. Such images increased the selection of design elements related to the climate and risk for participants identifying as female or as Democrat. For participants identifying as male or as Republican, the same images increased their selection of design elements to enhance community public space. The results demonstrate the positive effects of portraying the future in terms of encouraging focus on long-term sustainable design decisions for infrastructure systems.
\end{abstract}

Keywords: sustainable infrastructure; climate and risk; vivid imagery; behavioral decision-making; logistic modeling; envision rating system

\section{Introduction}

Present-day decisions about infrastructure will impact quality of life for future generations [1,2]. More frequent and severe storm events [3], longer and more extreme droughts [4], and rising sea levels [5] increasingly threaten communities and cities across the United States [6]. There is a global need to update infrastructure systems and to expand them to serve the billions who do not currently have access to infrastructure [7]. At the same time, existing infrastructure accounts for around one fifth of $\mathrm{CO}_{2}$ emissions. New infrastructure development must follow a different path. If not, the carbon output will exceed the planned reductions needed to avoid the worst effects of climate change.

Decisions made by a variety of stakeholders long before construction begins play an enlarged role in determining the costs and benefits of an infrastructure project [8]. Such decisions about infrastructure affect whether the community it serves becomes more or less vulnerable to the effects of climate change. How to account for climate change when making 
these types of design decisions about infrastructure is challenging because of its abstractness [9]. Its definition of "average weather over 30 years" [10] makes "climate" difficult to comprehend [11]. Design choices are challenging because changes in the environment occur during the lifespan of an infrastructure project [12].

The abstract qualities and psychological distance of effects from climate change are reflected in the public's perception of climate change. Generally, people associate climate change with distant places and times rather than the here and now $[11,13,14]$. The same is true of the engineers who design and construct infrastructure systems [15-17]. Infrastructure designers, whether professional or amateur, must properly deal with the abstractness of climate change in order to make accurate and long-lasting decisions about infrastructure.

Interventions that more vividly portray the future can help the public make future and distant events appear psychologically closer in time and space [11]. Vividly imagining future events is difficult [18]. People tend to undervalue future events and their consequences because of the abstractness of the future and its uncertainty. When considering climate change, experiencing the consequences of climate change reduces discounting and could increase the probability of taking action [19]. This may make the events and consequences seem much closer in time and space [11]. For instance, communities that have recently experienced disruptive weather events such as flooding are more willing to prepare for similar events in the future [20]. These communities perceive future events as more certain, and show greater willingness to take actions to better prepare for disruptive events [21].

Experiencing a disruptive event can inform subsequent decisions about the future because it changes how one perceives time and space. For example, in a recent study of twenty United States (U.S.) Coast Guard facility projects, all of the facilities were built to the minimum building code requirements. The exceptions were Coast Guard facilities that were previously damaged by hurricane winds and flooding; these were redesigned for resilience exceeding minimum code requirements [22]. Experiencing a disruptive event helped motivate those involved in Coast Guard building projects to take more protective action. Showing such disruptive events using images projecting the future promises a similar path towards making abstract future events more concrete and temporally closer [11]. Images portraying the future may help both the public and engineers to better anticipate these potential disruptions and prepare for them without actually having to experience real threats related to climate change, such as flooding.

This paper investigates whether concrete images of future outcomes can change the general public's design preferences related to environmental protection during the infrastructure development process. The public's design preferences matter because they can shape designers' scope and decision-making [23]. Periods of feedback from the public are often required when infrastructure projects invest taxpayer dollars. Participatory design processes where the public is intimately involved are increasingly common. Finding suitable channels to communicate regarding long-term impact on the environment and the benefits of sustainable design for the general public can help to improve design outcomes. The purpose of this study was to test whether vivid images of the future that represent the potential effects of climate change on infrastructure can help the public to better prioritize design alternatives that hold long-term benefits. To assess the effect of concrete images about the future development of infrastructure, we presented a decision-making scenario where participants were asked to select sustainable solutions in the context of designing upgrades to an airport in San Diego, California. The sustainable design options ranged from favoring social and community development to addressing climate change and preserving natural resources. The framework for defining the design options stemmed from the Envision rating system, which is a tool commonly used in the U.S. by over 6000 engineers to analyze and certify sustainable infrastructure projects [24]. The research presented in this paper extends previous work on using images of the future to help decision-makers value long-term perspectives by reducing temporal discounting and applying the results to design decision-making for sustainable infrastructure projects. 


\section{Background: Decision-Making about Sustainability and Climate Change}

\subsection{Vivid Experiences to Lift Psychological Distance of Climate Change Risks}

A barrier for decision makers to prioritize long-term sustainable design options lies in the psychological distance of climate change impacts $[12,21]$. The perceived distance to a future event (near or far) affects our mental representation of it; distant future events tend to be represented in an abstract manner, whereas near-future events have the propensity to be represented in a more concrete way [18,25]. Lack of representation of future events affects how decision-makers view the consequences of climate change, because the consequences happen slowly over generations [26]. Therefore, impacts of climate change are less concrete and specific in the short-term. As climate change impacts are perceived as distant in time and space, long-term gains in terms of sustainability are often not valued as much as short-term ones.

Personal experiences of climate change-related events, such as flooding or a hurricane, can reduce the social distance of climate change impact [27]. Real-world experiences of a disruptive event can change subsequent decisions about the future and change the perception of future uncertain events. For example, experiencing a flood provokes an increased feeling of worry and vulnerability toward future floods, which is a driver of adaptative actions to better prepare for inundations [28]. Waiting for such an event to occur before taking action leaves communities unnecessarily vulnerable to loss of life and economic insecurity. Behavioral interventions that illustrate future events or future selves can help to better envision how one will benefit (or suffer) from the outcomes of their current decisions [29]. According to [30], communication about future consequences and impacts of climate change is more effective than showing what has already happened. Vivid images depicting the future can provoke visceral reactions through mental simulations to alert people to the effects of climate change and motivate action to mitigate it [9]. The benefit of images or virtual worlds portraying the future is that stakeholders can experience the impacts of climate change without having to endure the real-world consequences.

Preliminary research in this vein is finding that more detailed and vivid experiences [31] lead to increased consideration of the future [32-34]. For instance, higher levels of immersion and self-reported presence enhance pro-environmental behavior [35]. Virtually experiencing growing a tree has a positive effect on environmental behavior engagement and the reduction of paper use [36]. Similarly, virtual experiences about the energy consumption of domestic hot water usage can elicit a reduction in hot water consumption [37]. Simulations of a disruptive flooding event increase participants' motivation to take preventive actions to mitigate such events [28]. Simulations can trigger a similar reaction to that of a real-life experience of a similar event [28]. Environmental psychology literature suggests that virtual experiences of the self and others in nature lead to greater feelings of interconnection between the self and nature as well as greater perceptions of environmental risks [38].

Reducing the perceived distance to an event by representing it in a more specific, detailed, and concrete way can increase perceived proximity to the event [11]. Although the effect of making climate change more proximate in order to influence peoples' motivation to take actions such as engaging in a sustainable behavior [21,39] is not yet clear $[11,27,30]$, it appears to be a relevant direction to follow. Using vivid experiences such as images depicting the future may help to reduce the perceived psychological distance of climate change-related events and encourage action toward more sustainable behaviors.

\subsection{Impact of Demographics and Identities on Decision-Making about Sustainability and Climate Change}

While we expect vivid images to aid decision-making among the public, there are reasons to expect these effects to differ across groups of people. For instance, cultural background has an effect on perception of time, concerns about global warming, and preparedness to adapt toward more sustainable behavior [39]. Another study suggests that gender and years of education are influencing factors in pro-environmental behaviors [40]. 
Women tend to be more concerned about the environmental crisis compared to men [40,41], and tend to consider environmental hazards such as natural disasters or nuclear power plants as a higher risk than men [42]. An averaging of results from studies conducted between 2001 and 2008 in the U.S. [41] found that women had greater understanding and concern about climate change than men. Several studies point toward an ideological and educational interaction where concerns about global warming for liberals or moderates increased with a higher degree of education, whereas concerns about global warming among conservatives tended to decrease with higher education $[43,44]$.

Political affiliation is another characteristic that strongly affects beliefs and decisionmaking about climate change. In the U.S., environmental concerns have typically been nonpartisan; however, that trend has changed within the last 40 years [43]. Policies to address climate change and global warming challenge foundational elements of the Republican Party and the conservative movement such as economic libertarianism, economic growth, and support for the free market [43]. In the 1990s, conservative think tanks in the U.S. promoted global warming counter-claims to policy-makers, Congressional hearings on global warming, and the general public aimed at critiquing the 1992 Kyoto Protocol [45]. This movement coincided with a Republican majority in the U.S. Congress which withheld pro-environmental regulatory policies and reduced funding for environmental research [45]. The partisan gap in the U.S. Congress on environmental issues is reflected in self-identified Democratic and Republican voters concerning their perception of global warming [46]. Democrats tend to hold stronger belief in anthropogenic climate change and support policies to address global warming, whereas most Republicans do not. For Republicans, the psychological distance of climate change-related events influences their concerns, as these increase the relative importance of events closer to home. Democrats tend to be more sensitive to both local and global climate-related issues $[27,47]$. Over the past decade, political affiliations in the U.S. have become part of a partisan social identity which reinforces the polarization of views on environmental protection and climate change that used to benefit from bipartisan support [43].

\section{Research Questions}

There is a consensus among scientists that the climate is changing and these changes will have negative impacts on both human communities and the environment [10]. Consensus from scientists about climate change, however, does not imply action from governments, businesses, community groups, and individuals to prevent it [40]. Realistic representations of future events induced by climate change offer the potential to engage an emotional response among the public and decision makers, enhance awareness about climate change and its implications, and drive action [48]. In this context, the research questions of our study are:

- What is the effect of images depicting the future impact of climate change on the selection of sustainable infrastructure design options?

- How do images that depict the future impact of climate change on infrastructure change participants' selection of sustainable design options as a function of differences in demographic variables (i.e., gender and political affiliation)?

We expected participants who received images depicting the future impact of climate change to produce more ambitious goals and to prioritize design solutions that evaluated long-term adaptability to climatic risks such as rising sea levels. We expected that political affiliation and gender would moderate any effect of the vivid images depicting the future impact of climate change.

\section{Methods}

\subsection{Data Collection}

A sample of people in the United States between the ages of 20-65 years old $(n=630)$ were provided with a case study about the redevelopment of the San Diego, California Airport. They were told about a USD one billion dollar proposed expansion designed to 
meet the airport's current and future travel demand. The project would add a new terminal and multiple gates, double the roadway area, and add more security lanes. This project was selected because of its coastal proximity and future risk of flooding in the next century. Data from the National Oceanic Atmospheric Administration (NOAA) study of Global and Regional Sea Level Rise offering scenarios for sea level rise through the year 2100 were provided to participants. These data showed that in the location of the airport, the sea level is expected to rise about $1.5 \mathrm{~m}$ by the year 2100 . In addition to the numerical sea-level rise data, participants viewed images of the current airport and renderings of the future expansion (Figure 1). Half of the participants received images portraying the current conditions (control group or CG, see Figure 1a), while the others received altered images portraying projected conditions in 2100 based on the NOAA sea level rise data (intervention group (IG); see Figure 1b).
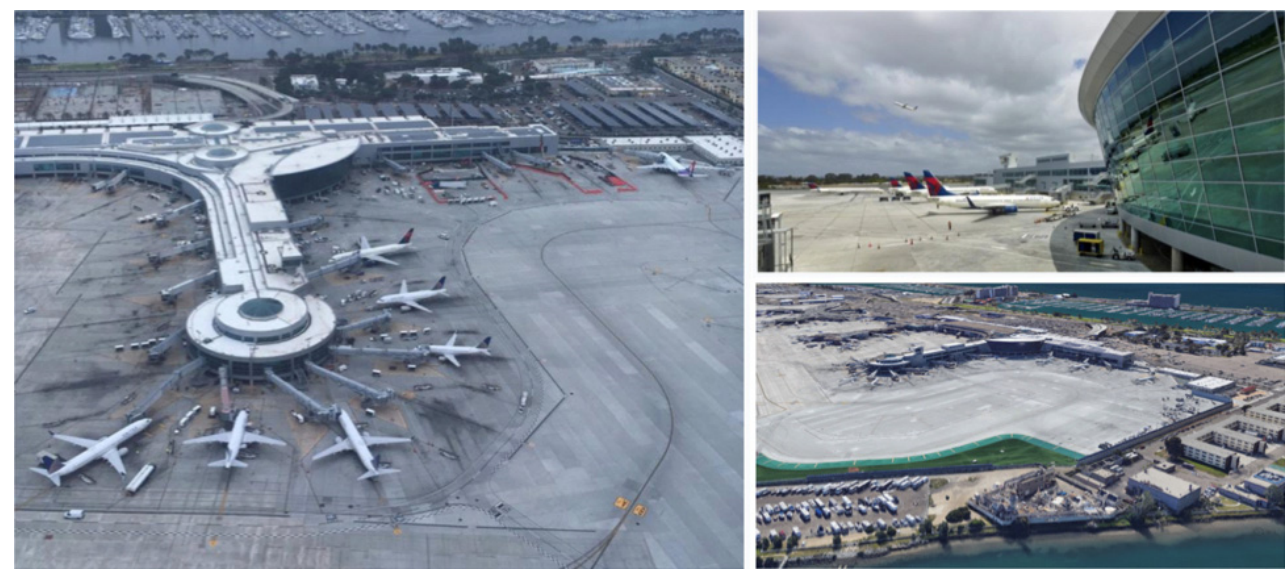

(a)
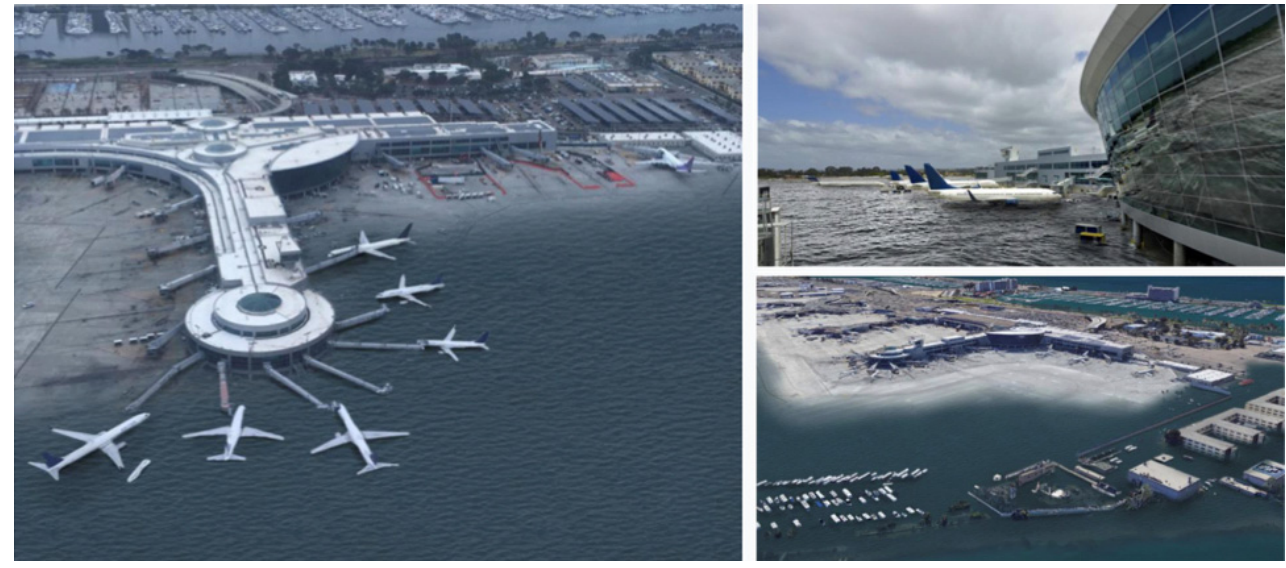

(b)

Figure 1. Top-down and exterior view photos given to participants: (a) non-altered photos for the control group (CG); (b) altered photos illustrating sea level in 2010 for the intervention group (IG).

Participants were then asked to select 7 out of 21 (i.e., one third) of the sustainable design options and features for the airport (Table 1). Sustainable design options were taken from the Envision rating system for sustainable infrastructure [24]. Envision is a leading rating system for sustainable infrastructure in the U.S. and is used to inform early design and goal-setting. Out of the 60 possible credits listed in Envision, 21 were explicitly relevant to the San Diego, California Airport expansion project and were chosen for the decision scenario. 
Table 1. Design elements from the Envision rating system provided to participants.

\begin{tabular}{|c|c|c|}
\hline & Design Element & Envision Categories \\
\hline $\begin{array}{l}\text { QL1 } \\
\text { QL2 } \\
\text { QL3 } \\
\text { QL4 } \\
\text { QL5 }\end{array}$ & $\begin{array}{l}\text { Enhance Community Health and Safety } \\
\text { Minimize Noise and Light Pollution } \\
\text { Improve Community Walkability and Transportation } \\
\text { Preserve Community History and Culture } \\
\text { Enhance Community Public Space }\end{array}$ & $\begin{array}{l}\text { Quality of life (QL): } \\
\text { Projects' impact on surrounding communities, } \\
\text { health and well-being of the social community } \\
\text { down to the individuals. }\end{array}$ \\
\hline $\begin{array}{l}\text { LD1 } \\
\text { LD2 } \\
\text { LD3 }\end{array}$ & $\begin{array}{l}\text { Encourage Collaboration Between Local Leadership and } \\
\text { Project Team } \\
\text { Establish a Sustainable Plan for Long-Term Maintenance } \\
\text { Grow Local Economy and Prosperity }\end{array}$ & $\begin{array}{l}\text { Leadership (LD): } \\
\text { Project team collaboration, management and } \\
\text { planning to ensure long-term holistic view of } \\
\text { project and its life cycle. }\end{array}$ \\
\hline $\begin{array}{l}\text { RA1 } \\
\text { RA2 } \\
\text { RA3 } \\
\text { RA4 }\end{array}$ & $\begin{array}{l}\text { Increase Use of Recycled Materials and Reduce Waste } \\
\text { Decrease Energy Consumption } \\
\text { Increase use of Renewable Energy } \\
\text { Decrease Water Consumption }\end{array}$ & $\begin{array}{l}\text { Resource Allocation (RA): } \\
\text { Projects' resources quantity, source and } \\
\text { characteristics, and their impact on the overall } \\
\text { sustainability of the project. }\end{array}$ \\
\hline $\begin{array}{l}\text { NW1 } \\
\text { NW2 } \\
\text { NW3 } \\
\text { NW4 } \\
\text { NW5 } \\
\text { NW6 }\end{array}$ & $\begin{array}{l}\text { Preserve Undeveloped Land and Natural Wetlands } \\
\text { Collect Stormwater Runoff to Protect Groundwater Quality } \\
\text { Reduce Pesticide and Fertilizer Impact } \\
\text { Protect Local Habitat and Reduce Invasive Species } \\
\text { Reduce Flooding and Protect Natural Streams } \\
\text { Protect Soil Health }\end{array}$ & $\begin{array}{l}\text { Natural World (NW): } \\
\text { Projects' capacity to minimize negative impact of } \\
\text { projects on natural world and interact with natural } \\
\text { system in a synergistic, positive way. }\end{array}$ \\
\hline $\begin{array}{l}\text { CR1 } \\
\text { CR2 } \\
\text { CR3 }\end{array}$ & $\begin{array}{l}\text { Reduce Greenhouse Gas Emissions and Air Pollutants } \\
\text { Decrease Climate Change Risk to Project } \\
\text { Set Goals to Reduce Climate Change Impact on Community }\end{array}$ & $\begin{array}{l}\text { Climate and Risk (CR): } \\
\text { Projects' ability to minimize pollutant emissions } \\
\text { and resilience to short-term hazards. }\end{array}$ \\
\hline
\end{tabular}

The credits fell into five categories defined in Envision: quality of life (QL), leadership (LD), resource allocation (RA), natural world (NW), and climate and risk (CR). Quality of life (QL) credits aim to assess a project's impact on surrounding communities, health, and the well-being of the social community down to the individual level. Leadership (LD) credits focus on the project team's collaboration, management, and planning to ensure a long-term holistic view of the project and its life cycle. Resource allocation (RA) credits deal with the quantity, source, and characteristics of the resources used for the project, as well as their impact on the overall sustainability of the project. The natural world (NW) category measures a project's capacity to minimize its negative impact on the natural world and interact with the natural system in a synergistic and positive way. The climate and risk (CR) section accounts for the project's ability to minimize pollutant emissions and resilience to short-term hazards.

Credits offered to participants included design options and features such as minimizing noise and light pollution (QL2), encouraging collaboration between local leadership and the project team (LD1), decreasing energy consumption (RA2), increasing use of renewable energy (RA3), collecting storm water runoff (NW2), decreasing climate change risk to the project (CR2), and setting goals to reduce the impact of climate change on the community (CR3) (see Table 1 for the list of credits provided to participants). We expected participants who viewed the vivid images of water level rising in the San Diego, California Airport expansion project would prioritize Climate and Risk credits over others more than participants who did not receive any interventions.

\subsection{Demographics and Belief in Climate Change}

After participants selected seven of the 21 credits (one third of the credits), additional questions about the participants' perceptions of climate change were asked in order to capture whether they thought that global warming is happening and how worried they are about global warming. Such questions are common in studies exploring the effect of demographics on views about climate change $[41,43]$. When participants were asked whether they think that global warming is happening, $78.6 \%$ responded yes, $9.3 \%$ responded no, 
and $12.1 \%$ were undecided. When asked whether they were worried about global warming, $80.2 \%$ answered they were somewhat worried $(35.3 \%)$ or very worried $(44.9 \%)$ about global warming, while the remaining $19.8 \%$ were not at all worried $(9.9 \%)$ or not very worried $(9.9 \%)$. For both questions, no significant difference between participants in the control group or intervention group was found. Therefore, our analysis was not subject to sampling bias in the participants' beliefs about climate change.

To determine participants' demographic characteristics, they answered questions about their political affiliation, occupation, level of education, and gender (Table 2). This study focused on gender and political affiliation, as those variables are known predictors of attitudes and behaviors concerning climate change beliefs [41-43]. Four political groups were provided in our survey: Democratic $(n=195)$; Republican $(n=227)$; Independent $(n=145)$; and no preference $(n=51)$, although we focus only on Democrats and Republicans in the results. In addition, of the 630 participants, 627 provided information about their gender $($ Female $=356$, Male $=271)$.

Table 2. Demographic description of the participants in the analyzed sample.

\begin{tabular}{|c|c|c|}
\hline Demographic Characteristics & Count of Participant $(n=630)$ & Distribution in \% \\
\hline \multicolumn{3}{|l|}{ Gender } \\
\hline Female & 356 & 56.5 \\
\hline Male & 271 & 43.0 \\
\hline $\mathrm{N} / \mathrm{A}$ & 3 & 0.5 \\
\hline \multicolumn{3}{|l|}{ Political affiliation } \\
\hline Republican & 227 & 36.0 \\
\hline Democrat & 195 & 31.0 \\
\hline Independent & 145 & 23.0 \\
\hline No preference & 51 & 8.1 \\
\hline $\mathrm{N} / \mathrm{A}$ & 12 & 1.9 \\
\hline \multicolumn{3}{|l|}{ Education } \\
\hline High school degree & 186 & 29.5 \\
\hline College/bachelor's degree & 270 & 42.9 \\
\hline Master's degree & 149 & 23.7 \\
\hline Doctoral degree & 25 & 4.0 \\
\hline \multicolumn{3}{|l|}{ Age range } \\
\hline Below 20 & 58 & 9.2 \\
\hline 20 to 25 & 121 & 19.2 \\
\hline 26 to 34 & 316 & 50.2 \\
\hline 35 to 54 & 134 & 21.3 \\
\hline 55 to 65 & 1 & 0.2 \\
\hline \multicolumn{3}{|l|}{ Occupation } \\
\hline Construction, extraction and maintenance & 20 & 3.2 \\
\hline Farming, fishing and forestry & 8 & 1.3 \\
\hline Government & 17 & 2.7 \\
\hline Management, professional and related & 208 & 33 \\
\hline $\begin{array}{l}\text { Production, transportation and } \\
\text { material moving }\end{array}$ & 22 & 3.5 \\
\hline Retired & 69 & 11.0 \\
\hline Sales and office & 48 & 7.6 \\
\hline Service & 109 & 17.3 \\
\hline Unemployed & 129 & 20.5 \\
\hline
\end{tabular}




\subsection{Data Analysis}

We analyzed participants' selection of the credits using generalized linear mixed models, specifically, mixed effects logistic regressions using the glmer() function in R. To address the first research question, we analyzed the likelihood of a participant selecting each of the 21 credits depending on a given condition by applying logistic regression [49]. To explore the effect of vivid interventions on participants grouped by demographic characteristics (research question two), we looked at the interaction between two predictors of credit selection, that is, condition and demographic characteristics. The dependent variable was whether participants selected a credit, while the independent variables were the group (i.e., the control and intervention group) and demographic characteristics (i.e., political affiliation and gender identity).

\section{Results}

5.1. Pictures Portraying the Future Impact the Selection of Infrastructure Redevelopment Design Options

All participants tended to select design elements related to health, safety and economy over design elements related to climate and risk, regardless of whether or not they received the vivid images. The most frequently chosen credits in both groups were growing the local economy and prosperity (LD3) and enhancing community and safety (QL1). Both ranked in the top seven selected design elements for both groups (Figure 2). Enhancing community and safety was selected the most by participants in the intervention group (59.6\%). Growing local economy and prosperity was selected more than $40 \%$ of the time by each group (control 43.5\%; intervention $42.9 \%$ ). Table 3 provides the interaction effect of the intervention for each of the 21 credits.

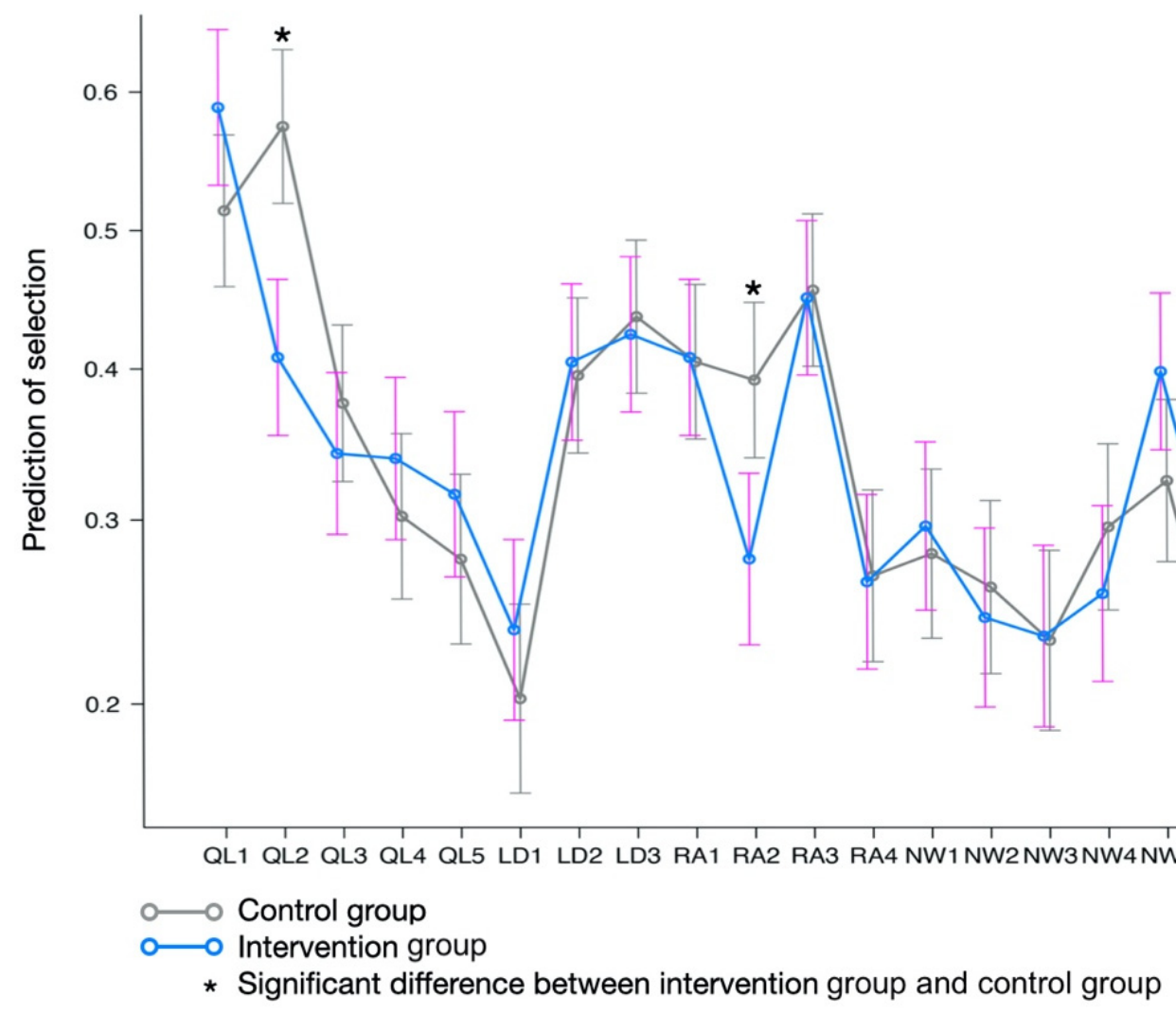

Figure 2. Probability of selecting a credit based on the typed of images viewed by participants: control group (non-altered photos) and intervention group (photos with projected sea-level rise). 
Table 3. Interaction effects of the intervention provided to participants on the selection of credit elements from the Envision rating system.

\begin{tabular}{|c|c|c|c|c|c|c|}
\hline Characteristic & Selected Count (\%) & Estimate & Statistic & $\mathrm{OR}^{1}$ & $95 \% \mathrm{CI}^{1}$ & $p$-Value \\
\hline Group effect on & dit selection & & & & & $0.008 *$ \\
\hline \multicolumn{7}{|c|}{ Intervention group effect on credit selection } \\
\hline QL1 & $188(59.6 \%)$ & 0.30 & 1.85 & 1.35 & $0.98,1.86$ & 0.07 \\
\hline QL2 & $127(40.3 \%)$ & -0.68 & -4.14 & 0.51 & $0.37,0.70$ & $3.50 \times 10^{-5 *}$ \\
\hline QL3 & $109(34.6 \%)$ & -0.15 & -0.88 & 0.86 & $0.62,1.20$ & 0.38 \\
\hline QL4 & $106(33.6 \%)$ & 0.17 & 0.97 & 1.18 & $0.84,1.66$ & 0.33 \\
\hline QL5 & $98(31.1 \%)$ & 0.18 & 1.07 & 1.21 & $0.85,1.71$ & 0.27 \\
\hline LD1 & $73(23.1 \%)$ & 0.20 & 1.03 & 1.22 & $0.83,1.79$ & 0.31 \\
\hline LD2 & $128(40.6 \%)$ & 0.04 & 0.23 & 1.04 & $0.75,1.43$ & 0.82 \\
\hline LD3 & 135 (42.9\%) & -0.05 & -0.32 & 0.95 & $0.69,1.31$ & 0.75 \\
\hline RA1 & $129(40.9 \%)$ & 0.01 & 0.07 & 1.01 & $0.73,1.40$ & 0.95 \\
\hline RA2 & $87(27.6 \%)$ & -0.53 & -3.04 & 0.59 & $0.42,0.83$ & $0.002 *$ \\
\hline RA3 & $141(44.8 \%)$ & -0.02 & -0.15 & 0.98 & $0.71,1.34$ & 0.88 \\
\hline RA4 & $83(26.3 \%)$ & -0.02 & -0.10 & 0.98 & $0.69,1.40$ & 0.93 \\
\hline NW1 & $95(30.1 \%)$ & 0.08 & 0.45 & 1.08 & $0.76,1.54$ & 0.66 \\
\hline NW2 & $76(24.1 \%)$ & -0.09 & -0.49 & 0.91 & $0.63,1.32$ & 0.63 \\
\hline NW3 & $73(23.1 \%)$ & 0.01 & 0.06 & 1.01 & $0.70,1.47$ & 0.95 \\
\hline NW4 & $82(26.0 \%)$ & -0.20 & -1.09 & 0.82 & $0.58,1.17$ & 0.28 \\
\hline NW5 & $124(39.3 \%)$ & 0.32 & 1.89 & 1.37 & $0.99,1.91$ & 0.06 \\
\hline NW6 & $80(25.3 \%)$ & 0.33 & 1.69 & 1.39 & $0.95,2.02$ & 0.09 \\
\hline CR1 & $100(31.7 \%)$ & -0.17 & -0.99 & 0.85 & $0.61,1.18$ & 0.32 \\
\hline CR2 & $88(27.9 \%)$ & 0.43 & 2.24 & 1.54 & $1.06,2.24$ & $0.03 *$ \\
\hline CR3 & $83(26.3 \%)$ & 0.06 & 0.35 & 1.07 & $0.74,1.53$ & 0.73 \\
\hline
\end{tabular}

${ }^{1} \mathrm{OR}=$ Odds Ratio, $\mathrm{CI}=$ Confidence Interval, ${ }^{*}$ sig. at $p<0.05$.

The results from the mixed effects logistic regression show a difference in the probability of adopting credits between the groups. The pictures depicting the effect of climaterelated events tend to have a positive effect on the selection of climate and risk credits (see the blue dot for CR2 and CR3 in Figure 2). Decreasing climate change risk to the project (Envision credit CR2) is selected significantly more by participants who received the images of flooding (for the intervention group, the odds ratio $=1.54, p<0.05$ in Table 3 ). In addition, the results from the logistic model indicate a significant difference in the selection of the credit to minimize noise and light pollution (QL2) and decrease energy consumption (RA2) (see the blue dot for QL2 and RA2 in Figure 2). Participants in the control group tended to select the QL2 credit and RA2 credit more often than participants in the intervention group, with an odds ratio of participants in the control group compared to the intervention group selecting QL2 of $0.51, p<0.05$ and RA2 of $0.59, p<0.05$ (Table 3).

\subsection{The Selection of Design Elements Changes Based on the Images Viewed by Participants and} Their Demographic Characteristics

The results regarding the second research question suggest that participants identifying as Democrats or as female tend to put a higher focus on design options that protected the natural environment and reduced climate risks to the airport. For participants identifying as male or as Republicans, the same images increased their selection of design elements 
that enhanced community safety and public space. The following two subsections describe these political and demographic differences in more detail.

5.2.1. Political Views Impact the Selection of Design Options for Infrastructure Redevelopment

We observed opposite trends in credit selection between participants who identified as Democrats and Republicans. Democrats tended to select all three credits related to climate and risk, namely, reduce greenhouse gas emissions and air pollutants (CR1), decrease climate change risk to the project (CR2), and set goals to reduce climate change impact on community (CR3), significantly more frequently than Republicans. Compared to Democrats, the odds ratio of Republicans selecting CR1 $=0.52, p<0.05, \mathrm{CR} 2=0.49, p<0.05$, and CR3 $=0.44, p<0.05$ (see Table 4). Participants who identified as Republicans favored community-oriented credits, namely, enhance community health and safety (QL1), preserve community history and culture (QL4), enhance community public space (QL5), and encourage collaboration between local leadership and project team (LD1), over climate and risk credits. Compared to Democrats, the odds ratio of Republicans selecting QL1 $=1.44$, $p<0.05, \mathrm{QL} 4=1.49, p<0.05$, QL5 = 1.61, $p<0.05$, and LD1 $=2.11, p<0.05$ (see Table 4).

Table 4. Interaction effects of political affiliation on the selection of credits.

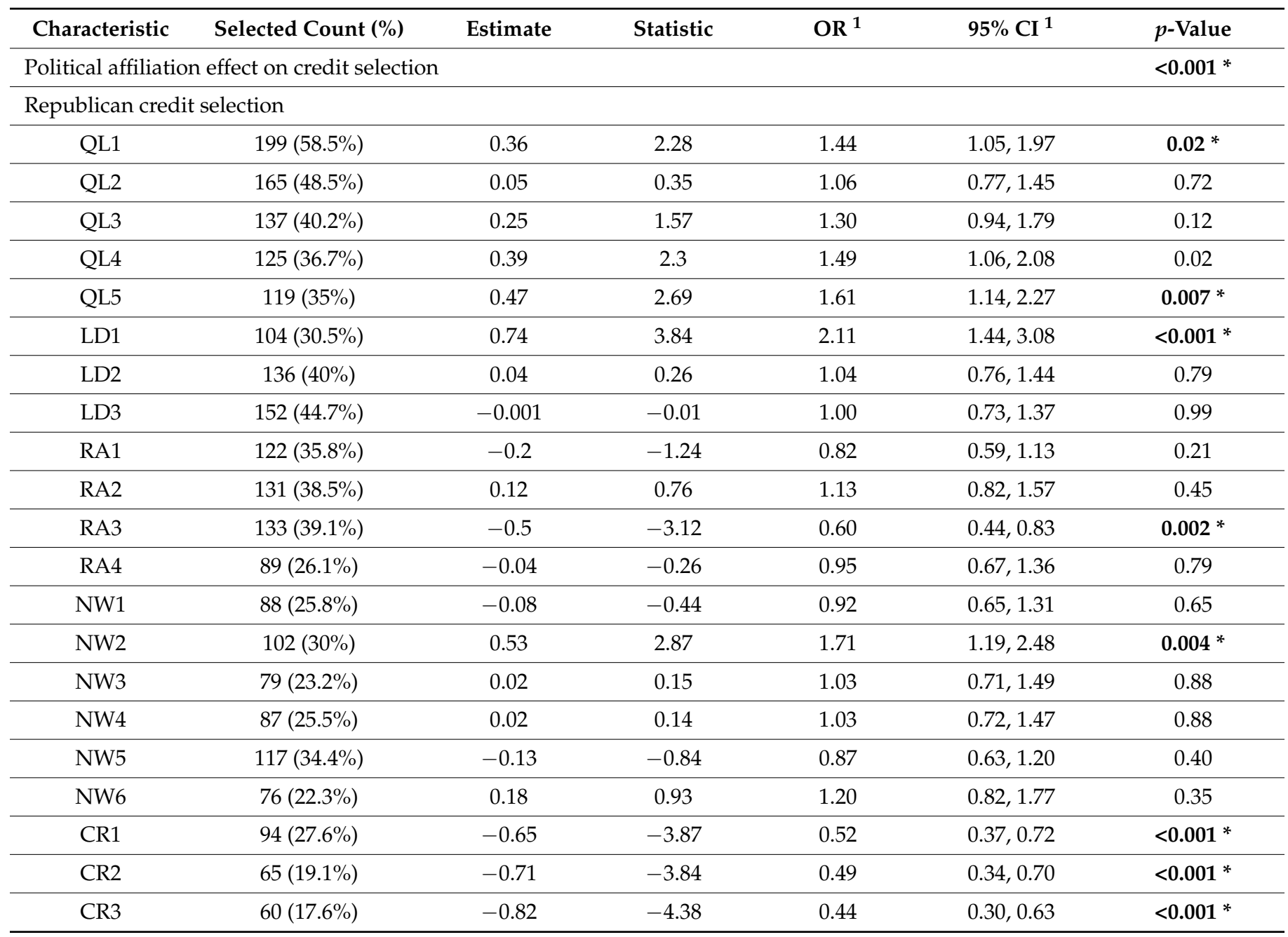

${ }^{1} \mathrm{OR}=$ Odds Ratio, $\mathrm{CI}=$ Confidence Interval, ${ }^{*}$ sig. at $p<0.05$.

Images portraying the future had more effect on participants with a Democratic political affiliation than a Republican political affiliation. When visualizing a simulation of water rising, people that identified as Democrats tended to select credits related to the Natural World section significantly more as compared to Democrats in the control group; 
the odds ratio of Democrats in the intervention group selecting NW5 $=1.86, p<0.05$, and NW6 $=2.16, p<0.05$. The effect of images on participants with a Republican political affiliation was limited to the Quality of Life credits. For people who identified as Republicans, images portraying the future significantly increased the selection of the "enhance community health and safety" credit (odds ratio of selecting QL1 $=2.31, p<0.05$ ).

5.2.2. Gender Identification Impacts the Selection of Design Options for Infrastructure Redevelopment

The results from the logistic regression show a trend in credit selection based on gender. Participants identifying as females were significantly more likely to select credits connected to future effects of climate change, specifically to reduce flooding and protect natural streams (NW5), reduce greenhouse gas emissions and air pollutants (CR1), decrease climate change risk to project (CR2), and set goals to reduce climate change impact on the community (CR3) (compared to participants identifying as females, the odds ratio of participants identifying as males selecting NW5 $=0.53, p<0.05$, CR1 $=0.61, p<0.05$, $\mathrm{CR} 2=0.72, p<0.05$, and CR3 $=0.51, p<0.05$, see Table 5). On the other hand, participants identifying as males tended to prioritize community-oriented credits such as enhancing community public space (QL5), improving community walkability and transportation (QL3), preserving community history and culture (QL4), and encouraging collaboration between local leadership and project team (LD1). Compared to participants identifying as females, the odds ratio of participants identifying as males selecting QL3 $=1.62, p<0.05$, QL4 $=1.51, p<0.05$, QL5 = 2.09, $p<0.05$, and LD1 $=2.30, p<0.05$ (see Table 5).

Table 5. Interaction effects of gender on the selection of credits.

\begin{tabular}{|c|c|c|c|c|c|c|}
\hline Characteristic & Selected Count (\%) & Estimate & Statistic & $\mathrm{OR}^{1}$ & $95 \% \mathrm{CI}^{1}$ & $p$-Value \\
\hline Gender effect on & t selection & & & & & $<0.001 *$ \\
\hline \multicolumn{7}{|c|}{ Participants identifying as male credit selection } \\
\hline QL1 & $228(56.0 \%)$ & 0.07 & 0.53 & 1.07 & $0.83,1.40$ & 0.59 \\
\hline QL2 & $179(43.9 \%)$ & -0.18 & -1.38 & 0.83 & $0.64,1.08$ & 0.18 \\
\hline QL3 & $178(43.7 \%)$ & 0.48 & 3.49 & 1.62 & $1.24,2.12$ & $<0.001 *$ \\
\hline QL4 & $146(35.8 \%)$ & 0.41 & 2.89 & 1.51 & $1.14,2.01$ & 0.004 * \\
\hline QL5 & $155(38.0 \%)$ & 0.74 & 5.03 & 2.09 & $1.57,2.78$ & $<0.001$ * \\
\hline LD1 & $125(30.7 \%)$ & 0.83 & 5.19 & 2.30 & $1.68,3.15$ & $<0.001$ * \\
\hline LD2 & $156(38.3 \%)$ & -0.10 & -0.72 & 0.91 & $0.69,1.18$ & 0.47 \\
\hline LD3 & $170(41.7 \%)$ & -0.03 & -0.25 & 0.97 & $0.74,1.26$ & 0.80 \\
\hline RA1 & $143(35.1 \%)$ & -0.30 & -2.17 & 0.74 & $0.57,0.97$ & $0.03 *$ \\
\hline RA2 & $155(38.0 \%)$ & 0.24 & 1.71 & 1.27 & $0.97,1.67$ & 0.09 \\
\hline RA3 & $171(42.0 \%)$ & -0.25 & -1.83 & 0.78 & $0.60,1.02$ & 0.07 \\
\hline RA4 & $128(31.4 \%)$ & 0.41 & 2.7 & 1.50 & $1.12,2.01$ & 0.007 * \\
\hline NW1 & $103(25.3 \%)$ & -0.30 & -2.04 & 0.74 & $0.55,0.99$ & $0.04 *$ \\
\hline NW2 & $113(27.7 \%)$ & 0.14 & 0.95 & 1.15 & $0.86,1.55$ & 0.34 \\
\hline NW3 & $97(23.8 \%)$ & -0.02 & -0.15 & 0.98 & $0.72,1.32$ & 0.87 \\
\hline NW4 & $95(23.3 \%)$ & -0.27 & -1.78 & 0.76 & $0.57,1.03$ & 0.07 \\
\hline NW5 & $116(28.5 \%)$ & -0.64 & -4.53 & 0.53 & $0.40,0.69$ & $<0.001$ * \\
\hline NW6 & $111(27.2 \%)$ & 0.52 & 3.25 & 1.68 & $1.23,2.29$ & $0.001 *$ \\
\hline CR1 & $112(27.5 \%)$ & -0.49 & -3.43 & 0.61 & $0.46,0.81$ & $<0.001$ * \\
\hline CR2 & $87(21.3 \%)$ & -0.33 & -2.09 & 0.72 & $0.53,0.98$ & $0.03 *$ \\
\hline CR3 & $81(19.9 \%)$ & -0.68 & -4.35 & 0.51 & $0.37,0.69$ & $<0.001$ * \\
\hline
\end{tabular}

${ }^{1} \mathrm{OR}=$ Odds Ratio, $\mathrm{CI}=$ Confidence Interval, ${ }^{*}$ sig. at $p<0.05$. 
The images portraying the future had a significant effect on the selection of specific credits for both gender categories. The vivid images portraying the future significantly increased the selection of the credit to decrease climate change risk to the project (CR2) and decreased the selection of the credit to minimize noise and light pollution (QL2). Compared to participants identifying as females in the control group, the odds ratio of participants identifying as females in the IG group selecting CR2 $=2.46, p<0.05$, and QL2 $=0.36$, $p<0.05$.

For participants identifying as males, the vivid images had a different effect. Vivid images did not increase their selection of climate-related design solutions; rather, they enhanced the probability of their selecting community health and safety (QL1), while decreasing the selection of the credit to decrease energy consumption (RA2). Compared to participants identifying as males in the control group, the odds ratio of participants identifying as males in the IG group selecting QL1 $=1.83, p<0.05$, and RA2 $=0.58, p<0.05$.

\section{Discussion}

Many challenges in addressing climate change issues today are connected to the abstract representation of climate change risks [9], the delayed impact and gratification for taking environmental actions, and the excessive discount rate placed on solutions to address climate change risks [50]. Investing today in climate change credits or policies such as reducing the greenhouse effect is a decision about redistributing income and making a sacrifice for the benefit of people in the distant future [51]. Using images portraying the future to provide an experience of climate change consequences engages an emotional response, and therefore offers a relevant solution to raise awareness among the general public about climate change [48]. Our results support this claim, as we found a significant positive effect of representing water level rise on the selection of design solutions to address climate and risks over community-oriented solutions. Results from the logistic regression analyses support the finding that the selection of the design options to decrease climate change risk (Envision credit CR2 and CR3) was selected more frequently by participants who viewed the images depicting future sea-level rise.

In addition, our findings show the importance of demographics and identity when dealing with investing in pro-environmental solutions. For example, political views have a large effect on decision-making about environmental issues [45,46]. The perception of consequences of global warming posing a threat to one's life or way of living in one's lifetime is affected by political views. Twice as many Democrats (around 50\%) see global warming as threat to society compared to Republicans (around 20\%) (Dunlap et al., 2016). Gender is another known factor that impacts risk perception as it applies to climate change risks [41,42]. People identifying as females place more importance on addressing climate change issues than people identifying as males, and our results align with this trend [41].

Our vivid intervention had a different effect depending on the demographic characteristics. In [52], the author emphasizes the importance of selecting the appropriate visualization material to target a specific audience about climate change because of the variability in human response to various vivid images. Personal interests, identity, and levels of engagement in pro-environmental behavior may vary. Using different types of imagery is a way to raise awareness to climate change issues by reaching a wider segment of the general public [53]. A risk in providing the same experience to all viewers is possibly generating a negative or boomerang effect on the viewer's perception of the climate change issue [54].

In our study, vivid interventions to aid in the selection of credits related to climate and risks had a stronger effect on participants identifying as female. In [47], the authors showed that messages approximating consequences of climate change on farmers' health increased polarization between Democrats and Republicans in climate change policy preferences. Democrats that received messages tended to increase their support for pro-environmental policies, whereas the same messages led Republicans to decrease their support for such policies. Our results show that images portraying the future had a significant positive effect 
on Democrats, leading to an increase in selecting Natural World credits (Reduce flooding and protect natural streams (NW5) and Protect soil health (NW6)). On the other hand, vivid images had a mixed effect on Republicans' selection of Climate and Risk credits, variably either decreasing it or increasing it. Other studies have pointed out the strong effect of ideology on willingness to engage with the anthropogenic impacts of climate change, regardless of the psychological distance of climate change related events [55,56]. They suggest that tailoring the framing of the psychological distance of climate change according to the political leanings of the audience is a relevant direction to follow in seeking to induce behavioral change. Depicting how climate change will affect the community's quality of life may resonate more with people who hold Republican-leaning political views. Depicting the effects of climate change on the natural world and our planet may resonate more with people who hold Democratic-learning political viewpoints. The difference in types of imagery and the framing of information regarding willingness to take action and influence design choices about infrastructure should be explored in future research.

\section{Limitations and Future Directions}

A limitation when using images portraying the future is the risk of perpetuating the problem by encouraging acceptance of climate change, as well as of perpetuating risk of disbelief due to a lack of credibility on the part of the virtual image [48]. Disbelief in the provided representation can have a negative effect on the viewer's decision and result in less willingness to take action. Identifying the right message for the right segment of viewers is necessary in order to avoid a boomerang effect. In other words, altering a message or representation to incite decision-making toward sustainable decisions needs to take into account participants' motivated reasoning generated by political partisanship and social identification. Another limitation is related to the number of variables included in the analysis. In the research presented here, the focus was on gender and political affiliation as demographic variables. The survey contains data about occupation and level of education that will be analyzed in future work.

In future work, effort will be put into tailoring vivid experience to each segment of decision-makers in order to increase the effectiveness of the interventions. Personas of decision-makers can be defined based on all the demographic information obtained from the survey, including gender, political affiliation, level of education and occupation. Fine-tuning the type of intervention to each persona may increase the performance of the intervention, and could be part of future work. Using increased levels of vividness, including three-dimensional renderings and virtual and augmented reality scenarios might have an impact on participants' willingness to take action toward sustainable design decisions [36], and could be explored in future work.

Future research might begin to consider how design preferences change over time. This study measured change in design preference immediately following participants viewing the vivid images portraying the future. How does time influence this shift in design preference? The length of time between viewing vivid images of the future and considering design options is not well understood. Testing the effects of multiple vivid interventions and integrating a temporal aspect into the design decision-making scenario that better mimics the time horizon of actual infrastructure design processes could provide more insight into the utility of this type of intervention, potentially improving and helping to shape design decisions about infrastructure.

\section{Conclusions}

This study analyzed the effect of images portraying future sea-level rise and demographic characteristics on the selection of sustainable design elements for an airport expansion project. Participants were provided information on sea-level rise before selecting which sustainable design elements the project team should prioritize. Half of the participants received images portraying the airport extension project with a simulation of the sea water level in 2100. The findings support a significant positive effect of representing 
water level rise on selecting design solutions to address climate and risks. In addition, the results highlight the importance of demographics and identity when dealing with investing in pro-environmental solutions. A better understanding of the ways in which interventions influence mental representations and inform decisions, and among which stakeholder groups, can help practitioners and policy-makers to target interventions more efficiently and effectively and to reduce implicit discount rates that exceed stated values about the future. Participatory design is more and more common in the development of infrastructure, and aims to include downstream users in the design process. Hence, it is important to find ways to communicate with the general public about challenges in sustainable design.

These results begin to demonstrate the effects of portraying the future through more vivid imagery. Immersion in the future via images may encourage a shift toward thinking about the future and climate change effects. Participants who were given the images portraying the future were significantly more likely to include the design option that decreased climate change risk to the project. Segments of participants behaved differently in their design choices depending on their political affiliation and gender. Democrats tended to prioritize climate and risks over community improvement, while Republicans tended to favor community improvement over environmental design decisions. Participants identifying as females placed more importance on addressing climate change issues than participants identifying as males. This study only explored the use of static imagery, which is not as immersive as Virtual Reality experiences. Future research could develop decisionmaking scenarios in Virtual Reality in order to increase the sense of presence and reality of the situation. Using vivid imagery is relatively low-cost compared to more physical or policy interventions. Tailoring experiences to align with viewers' individual ideology could improve underlying message comprehension, and possibly increase engagement in pro-environmental behavior.

Author Contributions: The paper was conceptualized by T.S., L.K., E.J.J. and E.U.W. The paper was written by all authors. The methodology was led by T.S. and analysis was led by J.M. All authors have read and agreed to the published version of the manuscript.

Funding: This material is based in part on work supported by The National Science Foundation through Grant CBET-1744246. Any opinions, findings, and conclusions or recommendations expressed in this material are those of the author(s) and do not necessarily reflect the views of the National Science Foundation.

Institutional Review Board Statement: The study was conducted in accordance with the Declaration of Helsinki, and approved by the Institutional Review Board (or Ethics Committee) of Virginia Tech Institutional Review Board (FWA00000572) (protocol code 20-193 and date of approval: 9 September 2021).

Informed Consent Statement: Informed consent was obtained from all subjects involved in the study.

Data Availability Statement: Data are contained within the article. Additional data are available on request to the corresponding author.

Conflicts of Interest: The authors declare no conflict of interest.

\section{References}

1. Lucena, J.; Schneider, J. Engineers, Development, and Engineering Education: From National to Sustainable Community Development. Eur. J. Eng. Educ. 2008, 33, 247. [CrossRef]

2. Pollalis, S.N.; Georgoulias, A.; Ramos, S.J.; Schodek, D. Infrastructure Sustainability and Design; Routledge: Abingdon, UK, 2013; ISBN 978-1-136-32039-2.

3. Ummenhofer, C.C.; Meehl, G.A. Extreme Weather and Climate Events with Ecological Relevance: A Review. Phil. Trans. R. Soc. B 2017, 372, 20160135. [CrossRef]

4. Cook, B.I.; Smerdon, J.E.; Seager, R.; Coats, S. Global Warming and 21st Century Drying. Clim. Dyn. 2014, 43, 2607-2627. [CrossRef]

5. Goddard, P.B.; Yin, J.; Griffies, S.M.; Zhang, S. An Extreme Event of Sea-Level Rise along the Northeast Coast of North America in 2009-2010. Nat. Commun. 2015, 6, 6346. [CrossRef] [PubMed] 
6. Hauer, M.E.; Evans, J.M.; Mishra, D.R. Millions Projected to Be at Risk from Sea-Level Rise in the Continental United States. Nat. Clim. Chang. 2016, 6, 691. [CrossRef]

7. United Nations. Transforming Our World: The 2030 Agenda for Sustainable Development; United Nations: Division for Sustainable Development Goals: New York, NY, USA, 2015.

8. Sen, P. Communicating Preferences in Multiple-Criteria Decision-Making: The Role of the Designer. J. Eng. Des. 2001, 12, 15-24. [CrossRef]

9. Weber, E.U. Experience-Based and Description-Based Perceptions of Long-Term Risk: Why Global Warming Does Not Scare Us (Yet). Clim. Chang. 2006, 77, 103-120. [CrossRef]

10. Intergovernmental Panel on Climate Change. Climate Change 2014: Synthesis Report; Intergovernmental Panel on Climate Change: Geneva, Switzerland, 2014; ISBN 978-92-9169-143-2.

11. Brügger, A. Understanding the Psychological Distance of Climate Change: The Limitations of Construal Level Theory and Suggestions for Alternative Theoretical Perspectives. Glob. Environ. Chang. 2020, 60, 102023. [CrossRef]

12. Pahl, S.; Sheppard, S.; Boomsma, C.; Groves, C. Perceptions of Time in Relation to Climate Change. WIREs Clim. Chang. 2014, 5, 375-388. [CrossRef]

13. Hanson-Easey, S.; Williams, S.; Hansen, A.; Fogarty, K.; Bi, P. Speaking of Climate Change: A Discursive Analysis of Lay Understandings. Sci. Commun. 2015, 37, 217-239. [CrossRef]

14. de Guttry, C.; Doring, M.; Ratter, B. How Distant Is Climate Change? Construal Level Theory Analysis of German and Taiwanese Students Statements. Int. J. Asian Soc. Sci. 2017, 7, 434-447. [CrossRef]

15. Shealy, T.; Valdes-Vasquez, R.; Klotz, L.; Potvin, G.; Godwin, A.; Cribbs, J.; Hazari, Z. Half of Students Interested in Civil Engineering Do Not Believe in Anthropogenic Climate Change. J. Prof. Issues Eng. Educ. Pract. 2017, 143, D4016003. [CrossRef]

16. Grubert, E. Civil Engineering's Internal Skepticism on Climate Change. J. Prof. Issues Eng. Educ. Pract. 2018, 144, 02518003. [CrossRef]

17. Katz, A.; Shealy, T.; Godwin, A. Civil Engineering Students' Beliefs about the Technical and Social Implications of Global Warming and When Global Warming Will Impact Them Personally and Others. In Proceedings of the 2020 ASEE Virtual Annual Conference Content Access, Online, 22-26 June 2020; p. 34285.

18. Trope, Y.; Liberman, N. Construal-Level Theory of Psychological Distance. Psychol. Rev. 2010, 117, 440-463. [CrossRef] [PubMed]

19. Reser, J.P.; Bradley, G.L.; Ellul, M.C. Encountering Climate Change: 'Seeing' Is More than 'Believing'. WIREs Clim. Chang. 2014, 5, 521-537. [CrossRef]

20. Weber, E.U. Climate Change Hits Home. Nat. Clim. Chang. 2011, 1, 25-26. [CrossRef]

21. Spence, A.; Poortinga, W.; Pidgeon, N. The Psychological Distance of Climate Change. Risk Anal. 2012, 32, 957-972. [CrossRef]

22. Lassiter, J.; Shealy, T. An Assessment of the Coast Guard's Engineering Operation and Design Decisions in Preparation for Sea Level Rise Due to Climate Change. In Proceedings of the International Conference on Sustainable Infrastructure 2017, New York, NY, USA, 26-28 October 2017; pp. 38-48.

23. Haus, M.; Erling Klausen, J. Urban Leadership and Community Involvement: Ingredients for Good Governance? Urban Aff. Rev. 2011, 47, 256-279. [CrossRef]

24. Envision ${ }^{T M}$ : A Rating System for Sustainabe Infrastructure; Institute for Sustainable Infrastructure: Washington, DC, USA, 2012.

25. Trope, Y.; Liberman, N. Temporal Construal and Time-Dependent Changes in Preference. Psychol. Rev. 2000, 110, 403-421. [CrossRef]

26. Jacquet, J.; Hagel, K.; Hauert, C.; Marotzke, J.; Röhl, T.; Milinski, M. Intra- and Intergenerational Discounting in the Climate Game. Nat. Clim. Chang. 2013, 3, 1025-1028. [CrossRef]

27. McDonald, R.I.; Chai, H.Y.; Newell, B.R. Personal Experience and the 'Psychological Distance' of Climate Change: An Inte-grative Review. J. Environ. Psychol. 2015, 44, 109-118. [CrossRef]

28. Zaalberg, R.; Midden, C.; Meijnders, A.; McCalley, T. Prevention, Adaptation, and Threat Denial: Flooding Experiences in the Netherlands. Risk Anal. 2009, 29, 1759-1778. [CrossRef] [PubMed]

29. Weber, E.U.; Johnson, E.J.; Milch, K.F.; Chang, H.; Brodscholl, J.C.; Goldstein, D.G. Asymmetric Discounting in Inter-temporal Choice: A Query-Theory Account. Psychol. Sci. 2007, 18, 516-523. [CrossRef] [PubMed]

30. Wang, S.; Hurlstone, M.J.; Leviston, Z.; Walker, I.; Lawrence, C. Climate Change from a Distance: An Analysis of Construal Level and Psychological Distance from Climate Change. Front. Psychol. 2019, 10, 230. [CrossRef]

31. Liebold, B. Cognitive and Emotional Processing of Virtual Environments: The Significance of Attentional Processes and Mental Models. Ph.D. Thesis, Technische Universität Chemnitz, Chemnitz, Germany, 2016.

32. Förster, J.; Friedman, R.S.; Liberman, N. Temporal Construal Effects on Abstract and Concrete Thinking: Consequences for Insight and Creative Cognition. J. Personal. Soc. Psychol. 2004, 87, 177-189. [CrossRef]

33. Smith, P.K.; Trope, Y. You Focus on the Forest When You're in Charge of the Trees: Power Priming and Abstract Information Processing. J. Pers. Soc. Psychol. 2006, 90, 578-596. [CrossRef]

34. Wakslak, C.J.; Trope, Y.; Liberman, N.; Alony, R. Seeing the Forest When Entry Is Unlikely: Probability and the Mental Representation of Events. J. Exp. Psychol. Gen. 2006, 135, 641-653. [CrossRef]

35. Fonseca, D.; Kraus, M. A Comparison of Head-Mounted and Hand-Held Displays for $360^{\circ}$ Videos with Focus on Attitude and Behavior Change. In Proceedings of the 20th International Academic Mindtrek Conference-AcademicMindtrek '16, Tampere, Finland, 17-18 October 2016; pp. 287-296. 
36. Ahn, S.J.; Fox, J.; Dale, K.R.; Avant, J.A. Framing Virtual Experiences: Effects on Environmental Efficacy and Behavior Over Time. Commun. Res. 2015, 42, 839-863. [CrossRef]

37. Bailey, J.O.; Bailenson, J.N.; Flora, J.; Armel, K.C.; Voelker, D.; Reeves, B. The Impact of Vivid Messages on Reducing Energy Consumption Related to Hot Water Use. Environ. Behav. 2015, 47, 570-592. [CrossRef]

38. Ahn, S.J.G.; Bostick, J.; Ogle, E.; Nowak, K.L.; McGillicuddy, K.T.; Bailenson, J.N. Experiencing Nature: Embodying Animals in Immersive Virtual Environments Increases Inclusion of Nature in Self and Involvement with Nature. J. Comput.-Mediat. Comm. 2016, 21, 399-419. [CrossRef]

39. Kim, K.; Ahn, S.J. The Moderating Role of Cultural Background in Temporal Framing: Focusing on Climate Change Awareness Advertising. Asian J. Commun. 2019, 29, 363-385. [CrossRef]

40. Kollmuss, A.; Agyeman, J. Mind the Gap: Why Do People Act Environmentally and What Are the Barriers to pro-Environmental Behavior? Environ. Educ. Res. 2002, 8, 239-260. [CrossRef]

41. McCright, A.M. The Effects of Gender on Climate Change Knowledge and Concern in the American Public. Popul. Environ. 2010, 32, 66-87. [CrossRef]

42. Finucane, M.L.; Slovic, P.; Mertz, C.K.; Flynn, J.; Satterfield, T.A. Gender, Race, and Perceived Risk: The "white Male" Effect. Health Risk Soc. 2000, 2, 159-172. [CrossRef]

43. Dunlap, R.E.; McCright, A.M.; Yarosh, J.H. The Political Divide on Climate Change: Partisan Polarization Widens in the U.S. Environ. Sci. Policy Sustain. Dev. 2016, 58, 4-23. [CrossRef]

44. Hamilton, L.C. Who Cares about Polar Regions? Results from a Survey of U.S. Public Opinion. Arct. Antarct. Alp. Res. 2008, 40, 671-678. [CrossRef]

45. McCright, A.M.; Dunlap, R.E. Defeating Kyoto: The Conservative Movement's Impact on U.S. Climate Change Policy. Soc. Probl. 2003, 50, 348-373. [CrossRef]

46. Dunlap, R.E.; McCright, A.M. A Widening Gap: Republican and Democratic Views on Climate Change. Environ. Sci. Policy Sustain. Dev. 2008, 50, 26-35. [CrossRef]

47. Hart, P.S.; Nisbet, E.C. Boomerang Effects in Science Communication: How Motivated Reasoning and Identity Cues Amplify Opinion Polarization About Climate Mitigation Policies. Commun. Res. 2012, 39, 701-723. [CrossRef]

48. Sheppard, S.R.J. Landscape Visualisation and Climate Change: The Potential for Influencing Perceptions and Behaviour. Environ. Sci. Policy 2005, 8, 637-654. [CrossRef]

49. Peng, C.-Y.J.; Lee, K.L.; Ingersoll, G.M. An Introduction to Logistic Regression Analysis and Reporting. J. Educ. Res. 2002, 96, 3-14. [CrossRef]

50. Caney, S. Climate Change, Intergenerational Equity and the Social Discount Rate. Politics Philos. Econ. 2014, 13, 320-342. [CrossRef]

51. Schelling, T.C. Intergenerational and International Discounting. Risk Anal. 2000, 20, 833-838. [CrossRef]

52. Nicholson-Cole, S.A. Representing Climate Change Futures: A Critique on the Use of Images for Visual Communication. Comput. Environ. Urban Syst. 2005, 29, 255-273. [CrossRef]

53. Rodrigues, L.; Gillott, M.; Waldron, J.; Cameron, L.; Tubelo, R.; Shipman, R.; Ebbs, N.; Bradshaw-Smith, C. User Engagement in Community Energy Schemes: A Case Study at the Trent Basin in Nottingham, UK. Sustain. Cities Soc. 2020, 61, 102187. [CrossRef]

54. Byrne, S.; Hart, P.S. The Boomerang Effect A Synthesis of Findings and a Preliminary Theoretical Framework. Ann. Int. Commun. Assoc. 2009, 33, 3-37. [CrossRef]

55. Feinberg, M.; Willer, R. The Moral Roots of Environmental Attitudes. Psychol. Sci. 2013, 24, 56-62. [CrossRef]

56. Markowitz, E.M.; Shariff, A.F. Climate Change and Moral Judgement. Nat. Clim. Chang. 2012, 2, 243-247. [CrossRef] 